\title{
Caça ao tesouro num espaço de múltiplas dimensões
}

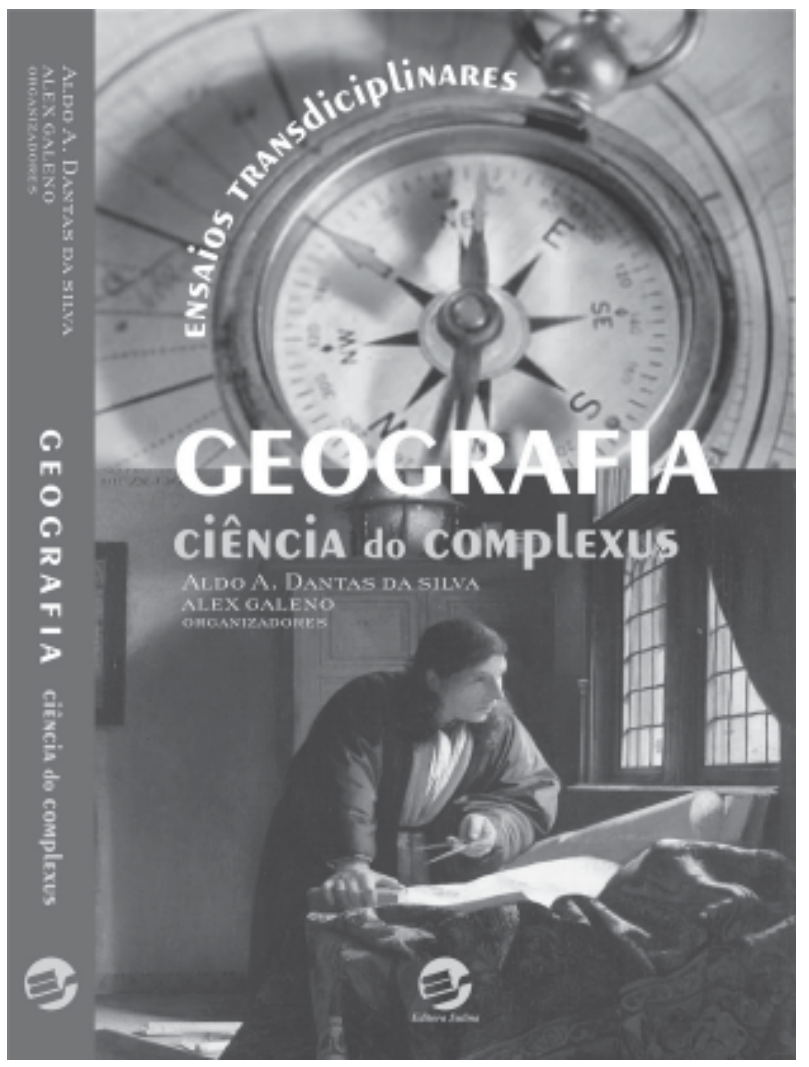

SILVA, Aldo A. Dantas da; GALENO, Alex (org.). Geografia: ciência do complexus - ensaios transdisciplinares. Porto Alegre: Sulina, 2004. 334 p.

\section{Margarida Maria Knobbe UFRN}

$\mathbf{U}$

m mapa inacabado, à guisa de introdução, e onze ensaios constroem nesta obra as pistas para uma caça aos tesouros da geografia. Uma frase de Marcel Proust, escolhida como epígrafe do livro, é o tiro de largada para a aventura: "Uma verdadeira viagem de descobrimento não é encontrar novas terras, mas ter um olhar novo".

O olhar novo, aqui, não se restringe aos estudos geográficos. Ao contrário, incita atitudes transversais, transcendendo disciplinaridades, conforme propõe Morin para as ciências da complexidade. E é este o primeiro tesouro desvelado: a identificação da presença de um conhecimento multidimensional na geografia, e formador de uma epistemologia da complexidade, por princípio. Nas palavras dos próprios organizadores do livro, "torna-se claro que a geografia não é a ciência da mera descrição fria dos elementos terrestres ou somente das coordenadas geográficas que servem de orientação ao homem. Ela deve ter por objetivo uma obra aberta que é o homem num planeta de encantamento misterioso e incerto" (p. 8).

Navegando, pois, na incerteza deste mar do inacabamento e da parcialidade que parasitam todo conhecimento, Maria da Conceição de Almeida penetra nos mistérios da emergência das chamadas ciências da complexidade. Elabora um "mapa inacabado", revelando a sucessão de bifurcações (Ilya Prigogine) e "os sintomas que permitem inferir o ponto de mutação em cujo interior gravita hoje a cultura científica" (p. 11).

A autora percorre os marcos gestores, as idéiasmãe, o atual "estado da arte" e as inquietações inerentes à nova ciência para anunciar alguns argumentos que circunstanciam a compreensão da complexidade. Entre eles, a imprevisibilidade, a nãolinearidade, a auto-organização, o inacabamento, as tensões entre dependência e autonomia e entre determinismo e liberdade.

O próprio “Mapa inacabado..." é resultado de uma auto-organização cognitiva a partir da experimentação desses argumentos pela pesquisadora em seu trabalho e em sua vida. É um texto ousado para uma introdução, mas muito bem-vindo por dar o tom epistemológico aos ensaios que se seguem. É igualmente uma matriz que serve como ponto de partida, interrompendo "seu traçado que perfila caminhos, vilas, ruelas e oásis da complexidade" para permitir "ao leitor o espaço para completá-lo" (p. 39).

Outros caminhos e descaminhos são percorridos pelos artigos de Michel Roux, Marcos de Carvalho, Aldo Dantas da Silva, Salete Kozel, Dirce Maria Suertegaray, Amélia Nogueira, Eugênia Dantas, Maria Helena Braga e Vaz da Costa, Alex Galeno, Maria Rodrigues e Anelino Francisco da Silva. Os ensaios dialogam com ciência, filosofia, religião e arte, transpassando geografias exteriores e interiores num espaço de múltiplas dimensões. 
A dimensão poética é enfatizada por Roux, um dos responsáveis pelo Atelier 28 "Espaços, habilidades dos territórios e Complexidade" do programa Europeu Modalização da Complexidade. Seu texto aposta no re-encantamento dos territórios a partir do que representam para seus habitantes. Segundo o autor, cabe aos geógrafos, especialistas de planejamento territorial, políticos e intérpretes de memórias de espaços, "procurar criar as condições de uma elucidação coletiva das representações do território que se entrecruzam, se entrelaçam de maneira contraditória, antagonista e também complementar" (p. 62).

O lugar habitado pela geografia dentro do território das ciências sociais é o tema de Marcos Bernardino de Carvalho. Entre outras, as idéias de Friedrich Ratzel (1844-1904) são revisitadas para chamar a atenção sobre a necessidade da aproximação entre as ciências históricas e políticas com a geografia, a despeito das resistências epistemológicas. "Nesse sentido", argumenta Carvalho, "constatar, na atualidade, a existência de preocupações que bem poderíamos caracterizar como antropogeográficas não deixa de ser um importante alento para os desenvolvimentos comuns do conjunto das ciências sociais" (p. 119).

As concepções de outro pensador, que remetem à aproximação entre as ciências naturais e humanas, são enfocadas no ensaio "A idéia de conexidade em Vidal de la Blache", de Aldo Dantas da Silva. Avesso ao pensamento disjuntivo, o criador da "moderna" geografia francesa "liga o humano e o físico, para fazer da geografia um verdadeiro estudo das relações entre cultura e natureza" (p. 135). Segundo Dantas, a geografia vidaliana é, sobretudo, uma forma de olhar as coisas, "uma paisagização do mundo".

Paisagem, mapa físico e mapa mental, espaço vivido e representações são noções apresentadas e discutidas também por Salete Kozel, em "Das 'velhas certezas' à (re)significação do geográfico", e por Dirce Maria Suertegaray, em "Ambiência e pensamento complexo: resignific(ação) da geografia". Kozel destaca "a importância dos aspectos socioculturais para a compreensão do espaço geográfico" (p. 178) eSuertegaray propõe, em termos similares, "geografar a educação".

Outra derivação da palavra geografia - geograficidade - é utilizada numa passagem do texto de Amélia Regina Batista Nogueira, que busca uma interpretação fenomenológica da relação homem-lugar. Nogueira utiliza a idéia de geograficidade de Eric Dardel (as várias maneiras pelas quais sentimos e conhecemos ambientes em todas as suas formas) para dialogar com diversos autores sobre os significados de lugar e espaço.

Também é possível viver e conhecer lugares e espaços através da literatura. "Nos caminhos de uma geografia complexa”, de Eugênia Dantas, esboça-se uma cartografia permitida pela linguagem, inspirada em Merleau-Ponty, de um lado, e em Ítalo Calvino, de outro. Eugênia Dantas sugere que a geografia pode ser entendida como "a narrativa do espaço": "Uma linguagem ativa reordena o campo de significados para ensinar ao leitor o que ele não sabia pensar nem dizer, tecendo os fios que enredam a geocartografia e a história da Terra" (p. 245-246).

O cinema, por sua vez, serve de álibi para a arquiteta Maria Helena Braga e Vaz da Costa projetar três tendências de representação sobre o espaço urbano: como obra de arte, como panorama e como espetáculo. O filme Matrix, comenta a autora, "constrói uma representação do que seria, do que consistiria, a cidade virtual que pode ser entendida como representação de um desconforto cultural causado pela confusão gerada pela nova maneira de percepção temporal e cultural" (p. 262).

Outras percepções são enfocadas no ensaio "Geopoéticas artaudianas", de Alex Galeno. A natureza poética e rebelde de Antonin Artaud (18961948) desvenda o abismo das geografias interiores. De acordo com Galeno, "como andarilho pelo mundo dos 'gênios híbridos' (Deleuze), Artaud cartografa regiões formadas por imensos continentes imaginais e habitadas pelas famílias dos que pensam e experimentam perigosamente a vida e as idéias" (p. 268).

Mas há uma terra onde realidades interiores e exteriores se fundem. É o que mostra o artigo "Diálogo com a escrita sobre o sertão". A autora, Maria Rodrigues, analisa a trajetória mítica das noções sobre o sertão a partir da Carta de Pero Vaz de Caminha. As construções discursivas tomadas como referências demarcam polissemias e descontinuidades: "Este percurso traduz a relação sociedade versus natureza, e expressa, através dos localismos e regionalismos, os elementos necessários para o entendimento de um ethos brasileiro forjado no campo do diverso" (p. 313).

Por fim, o livro traz um ensaio sobre outro espaço polissêmico: o sagrado. Em "Geografia, religião e representação social", Anelino Francisco da Silva expõe como a espacialidade da religião católica se difundiu pelo mundo ocidental. Uma difusão, contudo, habitada por uma dialética paradoxal, como descreve Mircea Eliade: “acessível e inacessível, único e transcendente, por um lado, repetível sem restrições por outro" (p. 334).

Essas são breves pistas sobre os conteúdos impressos em "Geografia: ciência do complexus". Impossível aprofundá-las numa resenha. Fica aqui, apenas, um convite aos leitores de qualquer área do conhecimento para participarem da caça aos tesouros transdisciplinares da geografia. A leitura não precisa necessariamente ser linear, seguindo a seqüência dos ensaios. Cada um é único, uma dobra, um recorte, um encaixe, embora seja complementar aos outros.

Penso que poderia comparar a organização deste livro à arte de Franz Weissmann (Áustria, 1911 Brasil, 2005); um inquieto quadrado aberto em fitas. $\mathrm{Ou}$, parafraseando o poeta Ferreira Gullar: uma escultura que "abre a matéria e mostra que dentro dela não há noite, há espaço, puro espaço, modalidade transparente de existência" mamecos 